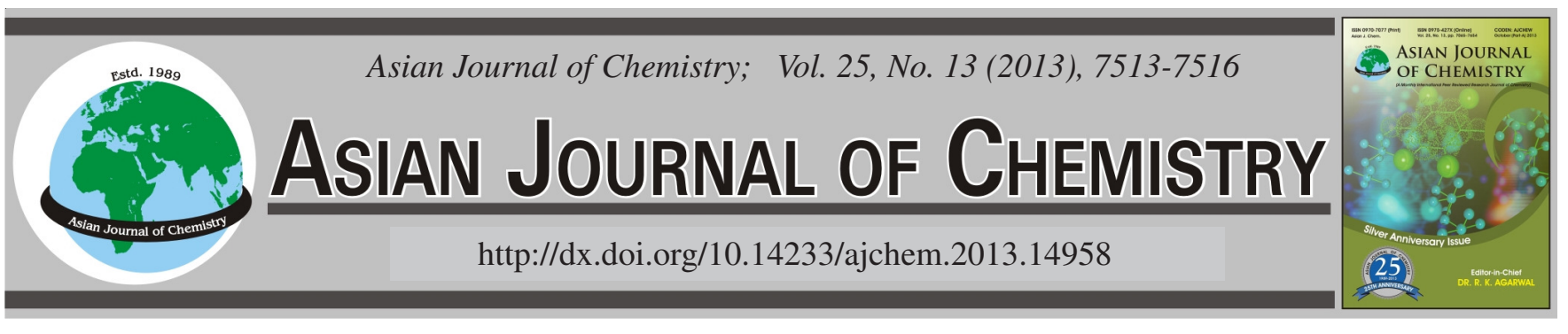

\title{
Viscometric Study of Bis(cinnamaldehyde) and Their Schiff Base Polymers in DMF and THF Solution at $30^{\circ} \mathrm{C}$
}

\author{
AmbreEn ShaH ${ }^{1}$ and Asif A. ShaH ${ }^{2, *}$
}

${ }^{1}$ Institute of Chemistry, University of Sindh, Jamshoro, Sindh, Pakistan

${ }^{2}$ Mehran University Institute of Science \& Technology Development, Jamshoro, Pakistan

*Corresponding author: Fax: +92 22 2771373; Tel: +92 22 2772325; E-mail: anashba_shah@yahoo.com

\begin{abstract}
Viscometric parameter is a simplest method to determine molecular shape, size and weight. Bis(cinnamaldehyde) and their Schiff base polymeric solutions were prepared in DMF and $\mathrm{THF}$ at $30^{\circ} \mathrm{C}$, to investigate viscometric study by dilute solution viscometry method. The intrinsic viscosity and viscometric constants of these solutions were calculated by six different equations such as Huggins, Kramer, Martin and Schulz-Blaschke equations by graphic extrapolation and Solomon-Ciuta, Deb-Chantterjee equations through a single point determination, which represents the advantage of being a faster method. The thermodynamic parameters e.g., $\Delta \mathrm{G}, \Delta \mathrm{S}$ and $\Delta \mathrm{H}$, were also calculated by equation related with dilute solution viscometry method. The molecular mass of polymers was determined by applying Mark-Howwink-Sakurada equation. The results obtained that the single point determination can be applied and Deb-Chantterjee equation showed to be the most appropriate for those calculations.
\end{abstract}

Key Words: Schiff base polymer, Dilute solution viscometry, Molecular weight, Thermodynamic parameters.

\section{INTRODUCTION}

4,4'-Methylenebis(cinnamaldehyde) (MBC) is formed from the parental compound cinnamaldehyde, having conjugated double bonds with aldehydic groups and successfully formed the Schiff base polymers with diamino compounds (such as ethylenediamine, 1,2-propylenediamine, 1,3propylenediamine, semicarbazide and thiosemicarbazide). Previously, the dialdehyde and some Schiff base polymers had been synthesized by polycondensation reaction and also characterized ${ }^{1}$. Characterization of this polymer has been done extensively by techniques like infrared spectroscopy (FTIR), ultraviolet/visible spectroscopy (U/V spectroscopy) and nuclear magnetic resonance (NMR). The thermal analysis as well viscosity measurement was observed from these derived Schiff base polymers ${ }^{2,3}$. The solubility of bis(cinnamaldehyde) and their Schiff base polymeric solutions were taken in highly polar solvents (DMF/THF) at $30^{\circ} \mathrm{C}^{4}$, to investigate viscometric study by dilute solution viscometry (DSV) method.

On the other hand, only some publications state viscometric measurements, but it will be helpful to match the results obtained from other techniques. However, viscometric measurement is a physical parameter and gives primary information about structure, size, shape and molecular weight of compounds ${ }^{5-7}$.
The viscometric method is a simple, inexpensive and sensitive analytical technique and also attractive to other methods. Dilute solution viscosity of dialdehyde and their derived Schiff base polymers were measured at various concentrations and temperatures ${ }^{8}$ by Oswald's viscometer. Every measurement was made at least three times. The adjustment of capillary position along vertical direction was taken and the proper control of temperature of system was maintained with Gallenkamp thermostatic water bath. Using the precaution, the variation of replicate measurements were observed with relative standard derivation (RSD) within $\pm 0.5 \%$.

The reduced viscosity (eqn. 1) provides a measurement of the polymer capacity of increasing the solution viscosity. When this parameter is extrapolated to infinite dilution, intrinsic viscosity value is obtained, in conditions where the macromolecules can be considered as isolated. Thus, from measurements of specific viscosity, it is possible to attain the intrinsic viscosity through graphic extrapolations. The specific viscosity determines the contribution of the solute to the viscosity of the solution. The quality of the solvent used, intrinsic viscosity values and some coefficients parameters are obtained from eqn. 6.

In order to apply these relations, practical determinations using different concentrations of polymer solutions are carried out by counting the efflux time of these solutions through a 
capillary $^{9,10}$, where the two parameters $\mathrm{K}$ and a are related to the "stiffness" of the chain and depend on the type of polymer, solvent and temperature ${ }^{11,12}$.

Dilute solution viscometry method for the determination of interaction of polymeric system has been studied. Ivana and his coworkers ${ }^{18}$ examined the viscometric study of high cis polybutadiene in cyclohexane and concluded that viscometric parameters determined by graphic extrapolation as well as single point determination are more rapid and suitable for high-cis polybutadiene. Philip ${ }^{14}$ investigated thermodynamics parameters and intrinsic viscosity measurements of hydrophobically-substituted water-soluble polymers and suggested that the intrinsic viscosity dependent on the thermodynamics function of nonionic polymer.

In the present study, the viscometry measurement of dilute solution of polymeric solutions with different concentrations has been performed based on DSV method. The viscometric parameters (intrinsic viscosity and constants values) of polymeric solution in THF have been obtained by extrapolation and single point determination as well as viscosity- average molecular mass were studied the perceptual difference of constant values of intrinsic viscosity by both methods and the average molecular mass were also compared.

\section{EXPERIMENTAL}

Cinnamaldehyde, ethylenediamine, 1,3-propylenediamine, semicarbazide, thiosemincarbarzide (E. Merck, Germany) and 1,3,5-trioxane (Fluka, Switzerland), glacial acetic acid, sulphuric acid (98\%), chloroform, $n$-hexane, tetrahydrofuran (THF) and dimethyl formamide (DMF) obtained from (Fluka, Switerzerland) were used. Pure nitrogen obtained from British Oxygen Company (BOC), Karachi was used. Meso-stilbenediamine was prepared as reported ${ }^{10}$ from benzaldehyde via hydrobenzamide, acetyl-meso-stillbenediamine to meso-stilbenediimine.

Preparation of 4,4'-methylenebis(cinnamaldehyde) (MBC) and their polymers: This dialdehyde and their different Schiff base polymers were prepared as reported methods ${ }^{11}$ and then the sample solutions were prepared by the procedure of dilute solution techniques, as below:

The dialdehyde (MBC) and five different polymeric solutions were prepared by adding the appropriate solvent $\mathrm{DMF} / \mathrm{THF}$ with different concentrations 0.02, 0.04, 0.06, 0.08, 0.1 and $0.12 \mathrm{~g} / 100 \mathrm{~mL}(\mathrm{w} / \mathrm{v})$ of solvent, (depending on the molecular mass), at room temperature $\left(30^{\circ} \mathrm{C}\right)$. For the extraplotation to infinite dilution, experimental determination was carried out by counting the eluent time of all sample solutions. By single point determination, the lowest value of dilution was chosen for calculations. At low concentration, the formation entanglement (error) of polymer among the macromolecules is minimized.

Characterization: The elemental micro-analysis was taken out by Elemental Micro-Analysis Ltd, Deven, U.K. Infrared spectra were recorded on a Nicolet Avatar 330 FT- IR (Thermo Nicolet Electron Corporation, USA) with attanulated total reflectance (ATR) accessory (Smart partner) within 4000$600 \mathrm{~cm}^{-1}$.
A parameter directly related to determination of viscometry is the intrinsic viscosity. Various mathematical equations are used in literature for calculating the intrinsic viscosity [ $\eta]$ of a polymeric solution, by graphic extrapolation (eqn. 1-4) and from a single point viscometry measurement of dilute solution (eqn. 5-6). These equations are as following:

$$
\begin{gathered}
\eta_{\text {red }}=[\eta]_{\mathrm{h}}+\mathrm{k}_{\mathrm{h}}[\eta]_{\mathrm{h}}^{2} \mathrm{c} \\
\ln \frac{\eta_{\mathrm{r}}}{\mathrm{c}}=[\eta]_{\mathrm{k}}-\mathrm{k}_{\mathrm{k}}[\eta]_{\mathrm{k}}^{2} \mathrm{c} \\
\ln \eta_{\mathrm{red}}=\ln [\eta]_{\mathrm{m}}+\mathrm{k}_{\mathrm{m}}[\eta]_{\mathrm{m}} \mathrm{c} \\
\eta_{\mathrm{red}}=[\eta]_{\mathrm{sb}}+\mathrm{k}_{\mathrm{sb}}\left[\eta_{\mathrm{sb}}\right] \eta_{\mathrm{sb}} \\
{[\eta]_{\mathrm{SC}}=\frac{\left[2\left(\eta_{\mathrm{sp}}-\ln \eta_{\mathrm{r}}\right)\right]^{1 / 2}}{\mathrm{c}}} \\
{[\eta]_{\mathrm{DB}}=\frac{\left(3 \ln \eta_{\mathrm{r}}+3 / 2 \eta_{\mathrm{sp}}^{2}-3 \eta_{\mathrm{sp}}\right)}{\mathrm{c}}}
\end{gathered}
$$

where: $\eta_{\mathrm{r}}=\mathrm{t} / \mathrm{to}$ is the relative viscosity (the ratio between elute time of polymeric solution and solvent), $\eta_{\mathrm{sp}}=$ specific viscosity $\left(\eta_{\mathrm{sp}}=\eta_{\mathrm{r}}-1\right),[\eta]_{\mathrm{h}}=\lim _{\mathrm{C} \rightarrow 0} \eta_{\mathrm{red}},[\eta]_{\mathrm{k}}=\lim _{\mathrm{C} \rightarrow 0} \eta_{\text {inh }},[\eta]_{\mathrm{m}}=$ $\lim _{\mathrm{C} \rightarrow 0} \ln \eta_{\mathrm{red}},[\eta]_{\mathrm{sb}}=\lim _{\mathrm{C} \rightarrow 0} \eta_{\mathrm{red}},[\eta]_{\mathrm{SC}}$ and $[\eta]_{\mathrm{DB}}$ are the intrinsic viscosities related to all above equations. $\mathrm{k}_{\mathrm{h}}, \mathrm{k}_{\mathrm{k}}, \mathrm{k}_{\mathrm{m}}$ and $\mathrm{k}_{\mathrm{sb}}$ are Huggins, Kramer, Martin and Schulz-Blaschke coefficient, respectively. Huggins and Kramer coefficients are related to chain conformation in the analysis conditions. While for many polymeric systems, the value of $\mathrm{k}_{\mathrm{sb}}$ was constantly found 0.28 , which is frequently applied in single point determination in many polymeric systems.

According to Mark-Sakurada equation (eqns. 5-6), the value of intrinsic viscosity changes with the molecular mass of polymers as:

$$
[\eta]=K M^{\mathrm{a}}
$$

where $\mathrm{K}$ and a are related to stiffness of chain conformation as well as depend on type of polymer, solvent and temperature. In average-viscosity molecular mass, the constants $\mathrm{k}=11.2 \times$ $10^{3} \mathrm{~mL} / \mathrm{g}$ and $\mathrm{a}=0.75$ were employed.

The viscosity measurements of dialdehyde (MBC) and their Schiff polymers (PMBCen, PMBCPR, PMBCSc and PMBCTSc, (Table-1) in DMF and meso-PMBCSt in THF with $0.02-0.12 \mathrm{~g} / \mathrm{dL}$ were noted within temperatures $30^{\circ} \mathrm{C}$ by using a suspended level viscometer (Technico ASTM 445). Each time $15 \mathrm{~mL}$ of solution was taken and average flow time of at least three readings was taken. The flow time (eluate time) of solvent at same condition was also noted. A Gallenkamp viscometer bath was used to control the temperature.

TABLE-1(a)

VARIOUS VISCOSITIES OF METHYLENEBISCINNAMALDEHYDE (MBC) AT DIFFERENT CONCENTRATION

\begin{tabular}{ccccc}
\hline Concentration & $\begin{array}{c}\text { Relative } \\
\text { viscosity }\end{array}$ & $\begin{array}{c}\text { Specific } \\
\text { viscosity }\end{array}$ & $\begin{array}{c}\text { Reduced } \\
\text { viscosity }\end{array}$ & $\begin{array}{c}\text { Intrinsic } \\
\text { viscosity }\end{array}$ \\
\hline 0.02 & 1.0063 & 0.0063 & 0.315 & 0.2489 \\
0.04 & 1.0150 & 0.0150 & 0.375 & 0.3289 \\
0.06 & 1.0267 & 0.0267 & 0.445 & 0.4089 \\
0.10 & 1.0505 & 0.0505 & 0.505 & 0.4889 \\
0.12 & 1.0678 & 0.0678 & 0.565 & 0.5689 \\
\hline
\end{tabular}




\begin{tabular}{ccccc}
\hline \multicolumn{5}{c}{ TABLE-1(b) } \\
\multicolumn{5}{c}{$\begin{array}{c}\text { VARIOUS VISCOSITIES OF SCHIFF BASE POLYMER } \\
\text { (PMBCen) AT DIFFERENT CONCENTRATION }\end{array}$} \\
\hline \multirow{2}{*}{ Concentration } & $\begin{array}{c}\text { Relative } \\
\text { viscosity }\end{array}$ & $\begin{array}{c}\text { Specific } \\
\text { viscosity }\end{array}$ & $\begin{array}{c}\text { Reduced } \\
\text { viscosity }\end{array}$ & $\begin{array}{c}\text { Intrinsic } \\
\text { viscosity }\end{array}$ \\
\hline 0.02 & 1.01208 & 0.01208 & 0.604 & 0.5841 \\
0.04 & 1.02656 & 0.02656 & 0.664 & 0.6641 \\
0.06 & 1.04344 & 0.04344 & 0.724 & 0.7441 \\
0.1 & 1.07840 & 0.07840 & 0.784 & 0.8241 \\
0.12 & 1.10128 & 0.10128 & 0.844 & 0.9041 \\
\hline
\end{tabular}

\begin{tabular}{ccccc}
\hline \multicolumn{5}{c}{ TABLE-1(c) } \\
\multicolumn{5}{|c}{ VARIOUS VISCOSITIES OF SCHIFF BASE POLYMER } \\
(PMBCPR) AT DIFFERENT CONCENTRATION \\
\hline \multirow{2}{*}{ Concentration } & $\begin{array}{c}\text { Relative } \\
\text { viscosity }\end{array}$ & $\begin{array}{c}\text { Specific } \\
\text { viscosity }\end{array}$ & $\begin{array}{c}\text { Reduced } \\
\text { viscosity }\end{array}$ & $\begin{array}{c}\text { Intrinsic } \\
\text { viscosity }\end{array}$ \\
\hline 0.02 & 1.01274 & 0.01274 & 0.637 & 0.5838 \\
0.04 & 1.02788 & 0.02788 & 0.697 & 0.6638 \\
0.06 & 1.04542 & 0.04542 & 0.757 & 0.7438 \\
0.10 & 1.08170 & 0.08170 & 0.817 & 0.8238 \\
0.12 & 1.10524 & 0.10524 & 0.877 & 0.9038 \\
\hline
\end{tabular}

\begin{tabular}{ccccc}
\multicolumn{5}{c}{ TABLE-1(d) } \\
\multicolumn{5}{c}{$\begin{array}{c}\text { VARIOUS VISCOSITIES OF SCHIFF BASE POLYMER } \\
\text { (PMBCSc) AT DIFFERENT CONCENTRATION }\end{array}$} \\
\hline \multirow{2}{*}{ Concentration } & $\begin{array}{c}\text { Relative } \\
\text { viscosity }\end{array}$ & $\begin{array}{c}\text { Specific } \\
\text { viscosity }\end{array}$ & $\begin{array}{c}\text { Reduced } \\
\text { viscosity }\end{array}$ & $\begin{array}{c}\text { Intrinsic } \\
\text { viscosity }\end{array}$ \\
\hline 0.02 & 1.01274 & 0.01274 & 0.637 & 0.5838 \\
0.04 & 1.02788 & 0.02788 & 0.697 & 0.6638 \\
0.06 & 1.04542 & 0.04542 & 0.757 & 0.7438 \\
0.10 & 1.08170 & 0.08170 & 0.817 & 0.8238 \\
0.12 & 1.10524 & 0.10524 & 0.877 & 0.9038 \\
\hline
\end{tabular}

\begin{tabular}{ccccc}
\multicolumn{5}{c}{ TABLE-1(e) } \\
\multicolumn{5}{c}{$\begin{array}{c}\text { VARIOUS VISCOSITIES OF SCHIFF BASE POLYMER } \\
\text { (PMBCSt) AT DIFFERENT CONCENTRATION }\end{array}$} \\
\hline \multirow{2}{*}{ Concentration } & $\begin{array}{c}\text { Relative } \\
\text { viscosity }\end{array}$ & $\begin{array}{c}\text { Specific } \\
\text { viscosity }\end{array}$ & $\begin{array}{c}\text { Reduced } \\
\text { viscosity }\end{array}$ & $\begin{array}{c}\text { Intrinsic } \\
\text { viscosity }\end{array}$ \\
\hline 0.02 & 1.01302 & 0.01302 & 0.651 & 0.6432 \\
0.04 & 1.02844 & 0.02844 & 0.711 & 0.7232 \\
0.06 & 1.04626 & 0.04626 & 0.771 & 0.8032 \\
0.10 & 1.08310 & 0.08310 & 0.831 & 0.8832 \\
0.12 & 1.10692 & 0.10692 & 0.891 & 0.9632 \\
\hline
\end{tabular}

\begin{tabular}{ccccc}
\multicolumn{5}{c}{ TABLE-1(f) } \\
\multicolumn{5}{c}{$\begin{array}{c}\text { VARIOUS VISCOSITIES OF SCHIFF BASE POLYMER } \\
\text { (PMBCTSc) AT DIFFERENT CONCENTRATION }\end{array}$} \\
\hline \multirow{2}{*}{ Concentration } & $\begin{array}{c}\text { Relative } \\
\text { viscosity }\end{array}$ & $\begin{array}{c}\text { Specific } \\
\text { viscosity }\end{array}$ & $\begin{array}{c}\text { Reduced } \\
\text { viscosity }\end{array}$ & $\begin{array}{c}\text { Intrinsic } \\
\text { viscosity }\end{array}$ \\
\hline 0.02 & 1.01516 & 0.01516 & 0.758 & 0.746 \\
0.04 & 1.03272 & 0.03272 & 0.818 & 0.826 \\
0.06 & 1.05268 & 0.05268 & 0.878 & 0.906 \\
0.10 & 1.09380 & 0.09380 & 0.938 & 0.986 \\
0.12 & 1.11976 & 0.11976 & 0.998 & 1.066 \\
\hline
\end{tabular}

The absolute viscosity $\eta$ was calculated from the following equation:

$$
\eta=\rho \beta t
$$

where " $\rho$ " is density, " $\beta$ " is calibration constant of viscometer and " $t$ " is the flow time of the liquid.

Thermodynamics parameters: The thermodynamic parameters of the solutions were determined from temperature dependence of absolute viscosity.
The activation energy $(\Delta G)$ was calculated from the equation:

$$
\Delta \mathrm{G}=2.303 \mathrm{RT} \log \left(\frac{\eta_{\mathrm{ab}} \mathrm{s}}{10^{-3}}\right)
$$

where $\mathrm{R}$ is gas constant and $\mathrm{T}$ is absolute temperature. A straight line was observed by plotting log nabs versus $1 / \mathrm{T}$.

The values of heat of activation of flow $(\Delta \mathrm{Hv})$ was calculated from slope $\mathrm{x}$ R.

The entropy of activation of viscous flow $(\Delta \mathrm{Sv})$ was calculated from equation:

$$
\Delta \mathrm{Gv}=\Delta \mathrm{Hv}-\mathrm{T} \Delta \mathrm{Sv}
$$

\section{RESULTS AND DISCUSSION}

The results of elemental micro-analysis of bis compound and their derived polymers also agreed closely to the expected values. Structural formula of polymers, were confirmed by elemental analysis and spectroscopic techniques. Biscinnamaldehyde and Schiff polymers were insoluble in water, methanol and ethanol, partially soluble in butanol, but soluble in acetone, chloroform, THF, DMF, DMSO and DMAc.

IR spectrum of Biscinnamaldehyde indicated strong bands at $1682 \mathrm{~cm}^{-1}$ due to $v(\mathrm{C}=\mathrm{O})$ vibrations of aldehyde. All the polymers indicate a characterized band within $1680 \mathrm{~cm}^{-1}$ due to $v(\mathrm{C}=\mathrm{N})$ vibrations. They were also indicated two to three bands within $1615-1500 \mathrm{~cm}^{-1}$ due to aromatic ring and $\mathrm{C}=\mathrm{C}$ vibration. The polymer $\mathrm{PMBCSc}$ indicated strong bands at $1654 \mathrm{~cm}^{-1}$ due to the presence of $\mathrm{v}(\mathrm{C}=\mathrm{O})$ groups, contributed by semicarbazide. PMBCTSc indicated a band at $1240 \mathrm{~cm}^{-1}$ of medium relative intensity, which could be attributed to $v(C=S)$ vibration and support the formation of the polymer.

The measurements of UV/VIS spectra were carried out in THF and DMF. Bis cinnamaldehyde indicates two absorption bands at 262 and $338 \mathrm{~nm}$ with the molar absorptivity of $2.3 \times 10^{4}$ and $1.0 \times 10^{4} \mathrm{~L} \mathrm{~mol}^{-1} \mathrm{~cm}^{-1}$ due to $\pi-\pi *$ transition in the benzoid rings and $\pi-\pi^{*}$ conjugated carbonyl groups, respectively. The polymers indicated three bands due to conjugated azomethine chromophores with $\pi-\pi^{*}$ conjugated $v(\mathrm{C}=\mathrm{C})$ groups.

The viscosity measurements of dialdehyde MBC and newly synthesized polymers formed were recorded within $30{ }^{\circ} \mathrm{C}$ with concentration within $0.02-0.12 \mathrm{~g} / \mathrm{dL}$ in THF /DMF. All the primary data for all polymers were defined in detail (Table-1). Fig. 1 showed the relation between $\log \eta_{\text {sp }}$ and $\log$ $\mathrm{c}[\eta]$ obtained for all samples. The linear relationship indicated that all attempt were observed in Newtonian flow. For graphic extrapolation, the viscometric data were determined from eqns. 1-4. The linear relations calculated by Huggins equation for all samples. Kramer, Martin and Schulz -Blaschke equations were concerned. Intrinsic viscosity $(\eta)$ is a function of molecular mass and it increased with increase in the molecular mass of polymer. The intrinsic viscosity values were obtained from all equation and their constants also calculated in (Table-2). As all intrinsic viscosity values calculated by both methods (graphic extrapolation and a single point viscometry determination) are almost equal, therefore, they were confirmed by the low percentual differences values (Table-3). 
TABLE-2

VISCOMETRIC CONSTANTS CALCULATED FOR BIS(CINNAMALDEHYDE) AND THEIR SCHIFF BASE POLYMERS

\begin{tabular}{cccccccc}
\hline Samples & {$[\mathrm{n}]_{\mathrm{h}}{ }^{\mathrm{a}}$} & {$[\mathrm{n}]_{\mathrm{k}}{ }^{\mathrm{a}}$} & {$[\mathrm{n}]_{\mathrm{m}}{ }^{\mathrm{a}}$} & {$[\mathrm{n}]_{\mathrm{sb}}{ }^{\mathrm{a}}$} & {$[\mathrm{n}]_{\mathrm{sb}}{ }^{\mathrm{b}}$} & {$[\mathrm{n}] \mathrm{s}_{\mathrm{cb}}{ }^{\mathrm{c}}$} & {$[\mathrm{n}]_{\mathrm{dc}}{ }^{\mathrm{c}}$} \\
\hline MBC & 2.2379 & 2.1579 & 2.2479 & 2.2529 & 2.1342 & 2.1291 & 2.1433 \\
PMBCen & 2.2674 & 2.1874 & 2.2774 & 2.2824 & 2.1492 & 2.1391 & 2.1502 \\
PMBCPR & 2.267 & 2.187 & 2.277 & 2.282 & 2.1502 & 2.1337 & 2.1512 \\
PMBCSc & 2.2673 & 2.1873 & 2.2773 & 2.2823 & 2.1511 & 2.1355 & 2.1521 \\
PMBCSt & 2.2675 & 2.1875 & 2.2775 & 2.2825 & 2.1527 & 2.1378 & 2.1537 \\
PMBCTSc & 2.2677 & 2.1877 & 2.2777 & 2.2827 & 2.1548 & 2.1383 & 2.1558 \\
\hline
\end{tabular}

${ }^{a}$ Calculated by graphic extrapolation. ${ }^{b}$ Calculated through a single point determination $\left(\mathrm{k}_{\mathrm{sb}}=0.28\right) .{ }^{\mathrm{c}} \mathrm{Calculated}$ through a single point determination.<smiles>O=C=Cc1ccc(Cc2ccc(C=CC=O)cc2)cc1</smiles>

(a)

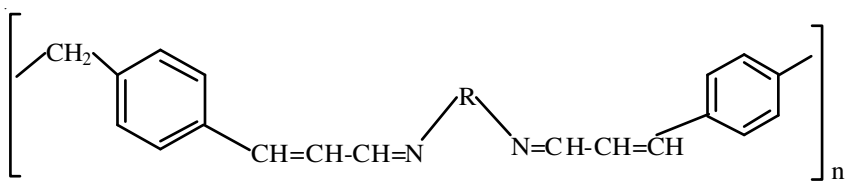

(b)

$\mathrm{R}=-$, PMBCen $=\mathrm{R}=\mathrm{CH}_{2} \cdot \mathrm{CH}_{2}, \mathrm{PMBCPR}=\mathrm{R}=\mathrm{CH}_{2} \cdot \mathrm{CH}_{2} \cdot \mathrm{CH}_{2}, \mathrm{PMBCSc}$ $=\mathrm{R}=\mathrm{NHCO}, \mathrm{PMBCTSc}=\mathrm{R}=\mathrm{NHCS}, \mathrm{PMBCSt}=\mathrm{R}=\mathrm{CH}(\mathrm{Ph})-\mathrm{CH}(\mathrm{Ph})$

Fig. 1. (a) Structure diagrams of MBC and (b) different Schiff base polymers

\begin{tabular}{|lccccc}
\multicolumn{7}{c}{ TABLE-3 } \\
\multicolumn{7}{c}{ ALL INTRINSIC VISCOSITY VALUES CALCULATED } \\
BY BOTH METHODS (GRAPHIC EXTRAPOLATION AND \\
\multicolumn{4}{c}{ A SINGLE POINT VISCOMETRY DETERMINATION) } \\
\hline \multicolumn{1}{c}{ Samples } & $\mathrm{kh}$ & $\mathrm{kk}$ & $\mathrm{km}$ & $\mathrm{k}$ sb & $\mathrm{kh}+\mathrm{kk}$ \\
\hline MBC & 0.1923 & -0.1693 & 0.1793 & 0.1593 & -0.9720 \\
PMBCen & 0.2714 & -0.2198 & 0.2498 & 0.2428 & -0.1311 \\
PMBCPR & 0.2828 & -0.2528 & 0.2758 & 0.2028 & -0.1342 \\
PMBCSc & 0.2858 & -0.2728 & 0.2828 & 0.2128 & -0.3510 \\
PMBCSt & 0.2968 & -0.2814 & 0.2898 & 0.2168 & -0.1357 \\
PMBCTSc & 0.3268 & -0.2738 & 0.3238 & 0.3031 & -0.1603 \\
\hline
\end{tabular}

The polymers were indicated higher values of intrinsic viscosities than bis compound. The absolute viscosity $\left(\eta_{\text {abs }}\right)$ for bis cinnamaldehyde was observed within 0.1910-0.4352 $\mathrm{mNS} / \mathrm{m}^{2}$ as compared to polymers PMBCen, PMBCPR, PMBCSc, PMBCSt and PMBCTSc were within 0.3541$0.4001,0.3612-0.499,0.385-0.502,0.4162-0.5117$ and 0.4281-0.553 $\mathrm{mNS} / \mathrm{m}^{2}$, respectively. The values of $\Delta \mathrm{Gv}$ for bis cinnamaldehyde were within $10.989-13.1287 \mathrm{KJ} \mathrm{mol}^{-1}$ as compared to all polymers range from $11.28-14.815 \mathrm{KJ} \mathrm{mol}^{-1}$. The value of $\Delta \mathrm{Gv}$ for dialdehyde and their polymers increased with an increase in temperature as well as concentration. The values of $\Delta \mathrm{Hv}$ increased with an increase in the concentration because more energy is required to overcome the flow of polymeric solution (Table-4). Similarly a decrease in the value of $\Delta \mathrm{Hv}$ was observed in polymers as compared to bis compound, it may be because of aggregation of the molecules in polymers. The values of $\Delta \mathrm{Sv}$ of MBC were -0.0013 to $-0.0081 \mathrm{~J} / \mathrm{K}$ as compared to their polymer (PMBCen) reange from -0.0112 to $-0.0197 \mathrm{~J} \mathrm{~K}^{-1}$. The negative sign of $\Delta \mathrm{Sv}$ for polymers show that during flow, the molecules are becoming more extended due to the uncoiling of the polymer molecules taking place in the solution.
TABLE-4

ENTHALPY OF ACTIVATION OF VISCOUS FLOW $\left(\Delta \mathrm{H}_{v}\right)$ FOR

DIALDEHYDE AND DRIVED SCHIFF BASE POLYMERS AT DIFFERENT CONCENTRATIONS $\left(\mathrm{KJ} \mathrm{mol}^{-1}\right)$

\begin{tabular}{lcccccc}
\hline \multirow{2}{*}{ Compounds s } & \multicolumn{7}{c}{ Concentration $(\mathrm{g} / \mathrm{dL})$} \\
\cline { 2 - 7 } & 0.02 & 0.04 & 0.06 & 0.08 & 0.1 & 0.12 \\
\hline MBC & 11.69 & 11.621 & 11.505 & 11.445 & 11.38 & 11.311 \\
PMBCen & 8.77 & 8.678 & 8.604 & 8.544 & 8.479 & 8.41 \\
PMBCPR & 8.52 & 8.455 & 8.425 & 8.358 & 8.296 & 8.227 \\
PMBCSc & 8.099 & 8.089 & 8.0798 & 8.0198 & 7.9548 & 7.8858 \\
PMBCSt & 7.86 & 7.8501 & 7.8404 & 7.7804 & 7.7154 & 7.6464 \\
PMBCTSc & 5.67 & 5.549 & 5.469 & 5.409 & 5.344 & 5.275 \\
\hline
\end{tabular}

\section{Conclusion}

In the present study, the viscosity behaviour of biscinnamaldehyde and derived Schiff base polymers observed by both methods graphic extrapolation and a single point determination. According to calculations, intrinsic viscosity as well as viscosityaverage mass results should be calculated by the determination of the flow time of compounds with any suitable concentration at a temperature. Schulz-Blaschke constant $(\mathrm{ksb}=0.28)$, employed to all polymeric systems in a single point determination, were also suitable for being applied in this work. As Huggin constants were lower than 0.5 indicating that DMF and $\mathrm{THF}$ are good solvents at $30{ }^{\circ} \mathrm{C}$. It was also verify by negative Kramer constant which were also indicate good solvents. Deb-Chantterjee equation shows more accuracy in calculation because it is independent of any predominated constant value and gives lower percentual difference as compare to other equations.

\section{REFERENCES}

1. M.Y. Khuhawar, A. Shah and M.A. Mughal, Chin. J. Polym. Sci., 25, 399 (2007).

2. K.I. Aly, J. Appl. Polym. Sci., 123, 3390 (2012).

3. R.M. Albu, E. Avram, I. Stoica, E.G. Ioanid and S. Ioan, Polym. Compos., 32, 1661 (2011).

4. A. Matsumoto, Y. Kaneda and H. Aota, J. Polym. Sci. Part A: Polym. Sci., 49, 3997 (2011).

5. T. Kanabara, Y. Kawai and K. Hasegawa, H. Morita and T. Yamamoto, J. Polym. Sci. Part A: Polym. Sci., 39, 3739 (2001).

6. T. Kaliyappan, S. Rajagopan and P. Kannan, J. Appl. Polym. Sci., 91, 494 (2004).

7. O. Melad, O. Abu-Teim and E. Sobeh, Asian J. Chem., 19, 883 (2007).

8. A. Shah, Ph.D Thesis, University of Sindh, Jamshoro, Pakistan (2011).

9. M.C. Delpech, F.M.B. Coutinho and M.E.S. Habibe, Polym. Test., 21, 411 (2002).

10. M.C. Delpech, F.M.B. Coutinho and M.E.S. Habibe, Polym. Test., 21, 155 (2002).

11. M.C. Delpech and C.M.F. Oliveira, Polym. Test., 24, 381 (2005).

12. C.I. Simionescu, S. Ioan and B.C. Simionescu, Eur. Polym. J., 23, 69 (1987).

13. I.L. Mello, M.C. Delpech, F.M.B. Coutinho and F.F.M. Albin, J. Braz. Chem. Soc., 17, 194 (2006).

14. P. Molyneux, J. Appl. Polym. Sci., 123, 657 (2012). 